\title{
The application of the TES technology in CHP heating system with Chinese demand profiles_-A techno-economic feasibility case study
}

\author{
Ruoyu Zhang ${ }^{1}$, Haichao Wang ${ }^{1, *}$, Xiaozhou $\mathrm{Wu}^{1}$, Xiangli $\mathrm{Li}^{1}$, and Lin Duanmu ${ }^{1}$ \\ ${ }^{1}$ Dalian University of Technology, Faculty of Infrastructure Engineering, China
}

\begin{abstract}
The thermal energy storage (TES) technology is an effective method to enhance the planning and the economy of the combined heat and power (CHP) plants, while it has still not been broadly promoted in China. In this paper we firstly establish a mathematical model for a Chinese CHP plant with TES. Then the EnergyPRO software is used to find the optimum type of the TES tank in a three-tariff electricity pricing market and the operation strategy of the CHP plant with the selected TES tank is studied. Thirdly, the economic benefits of the system with/without TES is evaluated. The results show that adding a TES tank with volume of $24000 \mathrm{~m}^{3}$ can significantly increase operational profits of the CHP system and reduce the use of peak-shaving heat source.
\end{abstract}

\section{Instruction}

With the acceleration of urbanization in China, the total district heating $(\mathrm{DH})$ demand in urban areas is increasing. At the end of 2016, the urban central heating area has reached 87 billion $\mathrm{m}^{2}$ [1]. For northern urban areas, coalfired CHP plants has become the main facility of DH system. Meanwhile, the design, operation and management (O\&M), as well as control technologies are developing slowly, which lead to a large extent of mismatch between DH demands and supplies in the CHP system.

According to the literature review, the TES technology is theoretically an effective method to solve the above problem.It can save the excess heat generated by the units and release the heat when needed[2]. T. Nuytten et al. to evaluate the thermal behavior of different TES technologies for coupling with a microCHP system in England. [3-5] introduce the operation strategy and optimization method in CHP pant, as well as the mathematical methods in finding the optimum type of TES capacity. The TES technology has still not been broadly promoted in China. One reason is that people haven't realized about the importance of TES on the O\&M of the CHP plant and the potential to enhance its economic benefit.

The EnergyPRO software has the ability to model and optimise operations of a DH system, especially suitable for CHP plants with TES tanks [6-7]. Lund et al. [8] use EnergyPRO to determine the optimal operation strategy of a CHP plant in Denmark, and point out that the optimization method and process for different regions are similar by adjusting the parameters of the software. In this paper we will establish a mathematical model for a CHP plant in China with a TES tank, using

* Corresponding author.

E-mail address:haichaowang@dlut.edu.cn (Haichao,wang).
EnergyPRO software to find the optimum type of the TES tank and studying the operation strategy as well as the economic benefit of the system. This study will help people realize the importance of optimizing the energy planning and the advantages of the TES technology assisting the CHP plant.

\section{The model establishment of the CHP with TES}

\subsection{Overview of the CHP plant}

The CHP plant is located in Shulan City, Jilin Province.It has two coal-fired back-pressure CHP units as basic heat source and one gas-boiler is also equipped as the peak boiler. Characteristics of each unit are given in Table 1. A TES tank is installed at the side of the heat source and connected directly with the primary network (Fig.1).

Table 1. Technical data of the units.

\begin{tabular}{|c|c|c|c|}
\hline & $\begin{array}{c}\text { Max. heat } \\
\text { production, } \\
\text { (MWh) }\end{array}$ & $\begin{array}{c}\text { Max. electrical } \\
\text { production, } \\
\text { (MWh) }\end{array}$ & $\begin{array}{c}\text { Heat- } \\
\text { power } \\
\text { ratio }\end{array}$ \\
\hline $\begin{array}{c}\text { CHP } \\
\text { unit }\end{array}$ & 98.5 & 35 & 2.86 \\
\hline $\begin{array}{c}\text { Peak } \\
\text { boiler }\end{array}$ & 116 & 0 & - \\
\hline
\end{tabular}

Most Chinese CHP plants only run in the period called heating season. The heating season in Shulan starts on October 15 and end on April 5 of the next year, totally 6 months. It is obtained that the calculated outdoor temperature $t_{w}=-24^{\circ} \mathrm{C}$ while the calculated indoor temperature $t_{n}=18^{\circ} \mathrm{C}$. So far, the heating area $\mathrm{F}$ 
undertaken by the CHP plant in heating season is $4.51 \times 10^{6} \mathrm{~m}^{2}$, with the average heating index $q_{f}$ of $44.4 \mathrm{~W} / \mathrm{m}^{2}$. The heat demand (HD) of the Shulan City in 2016-2017 heating season is calculated by degree-hour method [9]:

$$
\begin{aligned}
& H H=\left(1-\gamma_{d}\right)\left(18-t_{w j}\right) \\
& Q_{H D}(t)=\frac{q_{o} \cdot H H}{\left(t_{n}-t_{w}\right)}
\end{aligned}
$$

It can be seen from Fig. 2, during the initial and ending period of the heating season, HD is relatively low, sometimes even equals to 0 , while in the mid-term of the heating season, HD is rather high and sometimes beyond the maximum heat production of the CHP units which is $197 \mathrm{MWh}$, so the peak boilers need run at these periods. Meanwhile, the HD curve has strong fluctuation in the whole heating season. If the CHP units is fully operating in accordance with the changes in HD, especially for coal-fired units, the frequent adjustment of the unit operating parameters will bring the negative influence on both economic performance and safety of the unit [10]. If they maintain a base load to ensure operation efficiency, it will lead to the waste of heat especially in the beginning and ending of the heating season.

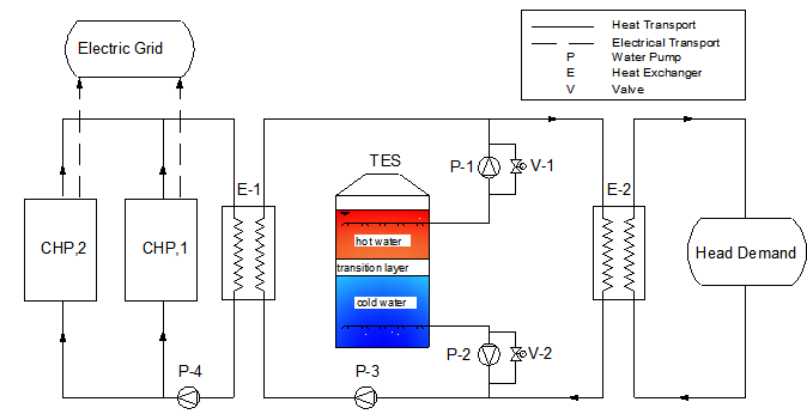

Fig. 1. Scheme of a CHP plant.

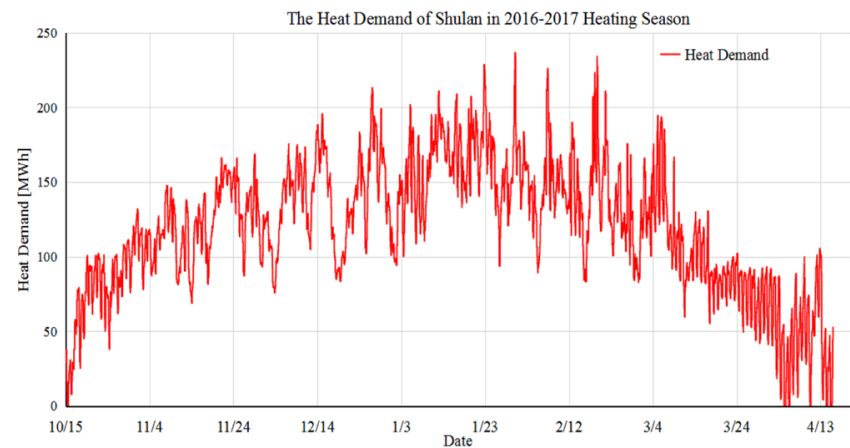

Fig. 2. The heat demand of Shulan in 2016-2017 heating season.

\section{2 the mathematical model}

The total amount of heat storage in one day is :

$$
Q_{T E S, s}=\sum_{t=1}^{24} k_{s} \cdot Q_{T E S, s}(t)
$$

The total amount of heat release in one day is :

$$
Q_{T E S, r}=\sum_{t=1}^{24} k_{r} \cdot Q_{T E S, r}(t)
$$

For the CHP plant, the hourly sale of heat and sale of electricity are respectively calculated by Eq.(5) and Eq.(6), while the hourly fuel cost by CHP units and peak boilers are calculated by Eq.(7). So the hourly operation income of the CHP plant can be calculated by Eq.(8). Considering the cost of TES tank, the NPV for a period of 15 years for the CHP plant can be calculated by Eq.(9) while $\mathrm{m}$ is the amount of months in heating season and $\mathrm{d}$ is the amount of days in each month.

$$
\begin{gathered}
I_{h}(t)=Q_{H D}(t) \cdot i_{h}(t) \\
I_{e}(t)=\left(P_{e 1}(t)+P_{e 2}(t)\right) \cdot i_{e}(t) \\
C_{f}(t)=\sum_{i=1}^{2}\left(P_{h i}(t)+P_{e i}(t)\right) \cdot c_{1}(t)+H_{p e a k}(t) \bullet c_{2}(t) \\
I_{A}(t)=I_{h}(t)+I_{e}(t)-C_{f}(t) \\
N P V=\sum_{t_{\text {year }}=1}^{15}\left[\frac{\sum_{t_{\text {monh }}}^{m} \sum_{t_{\text {day }}}^{d} \sum_{t=1}^{24} I_{A}(t)}{(1+r)^{t_{\text {year }}}}\right]-C_{T E S}
\end{gathered}
$$

\subsection{The constraints of the model}

\subsubsection{The equality constraints of the model:}

Eq.(10) means the heat supply of CHP plant should always meets HD. Only considering the problem of short-term heat storage in this paper, Eq.(11) means the amount of heat storage is always equal to the amount of heat release within one day. Besides, the relation between the heat production and the electricity production of the back-pressure units could be regarded approximately as in linear relationship described by Eq.(12) .

$$
\begin{gathered}
\sum_{i=1}^{2} P_{h i}(t)-k_{s} \cdot Q_{T E S, s}(t)+k_{r} \cdot Q_{T E S, r}(t)=Q_{H D}(t)(i=1,2) \\
Q_{T E S, s}=Q_{T E S, r} \\
P_{h i}(t)=C_{m} P_{e i}(t)(i=1,2)
\end{gathered}
$$

\subsubsection{The inequality constraints}

The following relationship should be satisfied among $Q_{T E S, s,} Q_{T E S, r}$ and the capacity of the TES tank $Q_{T E S}$ within one day:

$$
Q_{T E S, r} \leq Q_{T E S, s} \leq Q_{T E S}
$$

The heat production and electricity production of each CHP unit meets the limit as it is shown in the following inequations:

$$
\begin{aligned}
P_{h i \text {,min }}(t) & \leq P_{h i}(t) \leq P_{h i, \text { max }}(t)(i=1,2) \\
P_{e i, \text { min }}\left(P_{h i}(t)\right) & \leq P_{e i}(t) \leq P_{e i, \text { max }}\left(P_{h i}(t)\right)(i=1,2)
\end{aligned}
$$

\section{Analysis of the calculating results}

3.1 Selection of optimal volume of TES tank 
In this paper, the 15-year NPV maximization of the system is taken as the object function to determine the optimal volume of the TES tank and the EnergyPRO software is adopted to solve the system model in 2.2. In this case, temperature difference at the hot and cold water ends of the TES tank is fixed as $35^{\circ} \mathrm{C}$ and the effective volume covers $90 \%$ of the total volume. Taking the peak-valley price into consideration, relevant economic data of the CHP plant is shown in the Table 2.

Table 2. Economic data.

\begin{tabular}{|c|c|}
\hline Heat price, USD/MWh & 14.5 \\
\hline $\begin{array}{c}\text { Electricity peak-price, USD/MWh } \\
(8: 00 \text { am 11:00am \& 18:00pm 23:00pm) }\end{array}$ & 88.5 \\
\hline $\begin{array}{c}\text { Electricity high-price, USD/MWh } \\
(11: 00 \mathrm{am} \sim 18: 00 \mathrm{pm})\end{array}$ & 57.0 \\
\hline $\begin{array}{c}\text { Electricity valley-price, USD/MWh } \\
(23: 00 \mathrm{pm} \sim 8: 00 \mathrm{am})\end{array}$ & 28.5 \\
\hline Coal cost, USD/t & 24 \\
\hline Natural gas cost, USD/Nm ${ }^{3}$ & 0.6 \\
\hline TES cost, USD/m ${ }^{3}$ & 450 \\
\hline Discount rate & $6 \%$ \\
\hline
\end{tabular}

From the perspective of improving the revenue of the CHP plant, suppose the TES tank stores heat as much as possible at the peak and high value of the electricity price to improve the electricity production of the units during these periods, while releasing heat at the valley value period, which is a rather reasonable operation strategy. In the calculation steps, we set the content of TES tank is empty at 8 a.m. each day and start TES tank to store heat from that moment.

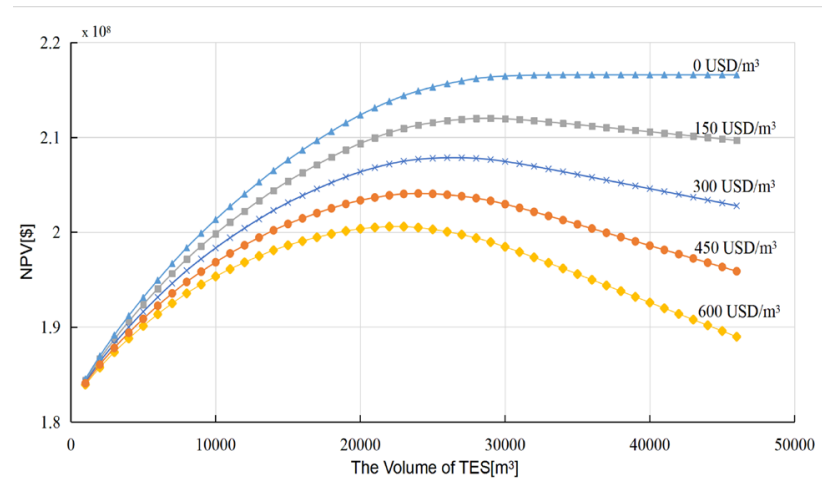

Fig. 3. 15-year NPV of CHP with different value of $C_{T E S}$

The optimization results under different $C_{T E S}$ are shown in the Fig.3. When $C_{T E S}$ is 0 , the 15-year NPV value grows with the set volume of the TES tank increasing. When the volume of the TES tank is about $35000 \mathrm{~m}^{3}$, the 15 -year NPV value of the system tends to be fixed value. If the volume of the TES tank is larger than $35000 \mathrm{~m}^{3}$, the 15 -year NPV of the system will increase no longer because there is no more heat in units to store in the TES tank. When taking into consideration of $C_{T E S}$, the 15-year NPV value would decrease as the volume of the tank beyond the optimal volume, and the larger the $C_{T E S}$ is, the smaller the 15 -year NPV value is. Besides, the optimal volume to get the maximum 15year NPV value would decrease with $C_{T E S}$ increasing. According to the relevant market price at home and abroad, we take the $C_{T E S}$ of the TES tank as $450 \mathrm{USD} / \mathrm{m}^{3}$, based on which the optimal volume of the TES tank is $24000 \mathrm{~m}^{3}$ corresponding to the storage capacity $876 \mathrm{MWh}$.

\subsection{The optimal operation strategy}

EnergyPRO could calculate the production priority of each unit by the target of optimization and obtain the optimal operation strategy. The simulation is conducted on Shulan CHP with the TES tank volume of $24000 \mathrm{~m}^{3}$. At the initial stage (with the results of first 30 days of the heating season as the example in Fig.4), the amount of heat storage in CHP units is abundant so the capacity of the TES tank could almost be taken full use. Unit 1 and unit 2 try to run at full load during the period when the electricity price at peak and high values. The heat produced by the CHP units could meet the HD as well as the heat storage requirement of the TES tank till reach its storage capacity. The TES tank releases heat at the valley-price period. Since the heat load is low, heat release of the TES could basically satisfy heat demands. During this period, the CHP units could product less heat or stop running. At ending stage of the heat season, the operation strategy of the system is similar to that of the initial stage (as shown in the Fig.5).

In the mid-term (taking January which has the lowest average temperature in the heating season as the example in Fig.6), the HD at the user side is rather high. It could be seen that the time when units operate at full load increases obviously and in some days, the content of TES could not even be filled. This is because in these cases the units need to provide more heat to the users, so there is not enough heat to be stored into the TES tank. During the heat release period of the TES tank, it is possible that the heat supplied by CHP units and the TES tank can't satisfy the HD, under which circumstance the peak boilers is required to start to meet the HD on the user side (the pink part in the diagram).

In addition, We suppose the CHP units is fully running in accordance with the HD curve before adding a TES tank, then it can be found the stable operation time of the CHP units in the whole heating season is greatly extended after the TES tank is configured.

\subsection{Economic analysis}

Table 3. Economic comparison in the heating season.

\begin{tabular}{|l|c|c|c|c|}
\hline & $\begin{array}{c}\text { sale of } \\
\text { heat } \\
\text { )USD) }\end{array}$ & $\begin{array}{c}\text { sale of } \\
\text { electricity } \\
\text { (USD) }\end{array}$ & Fuel cost & $\begin{array}{c}\text { Operation } \\
\text { (USD) }\end{array}$ \\
\hline Case A: & 7724424 & 10242280 & 5124180 & 12842525 \\
\hline Case B: & 7724424 & 12442623 & 4982357 & 15184690 \\
\hline
\end{tabular}




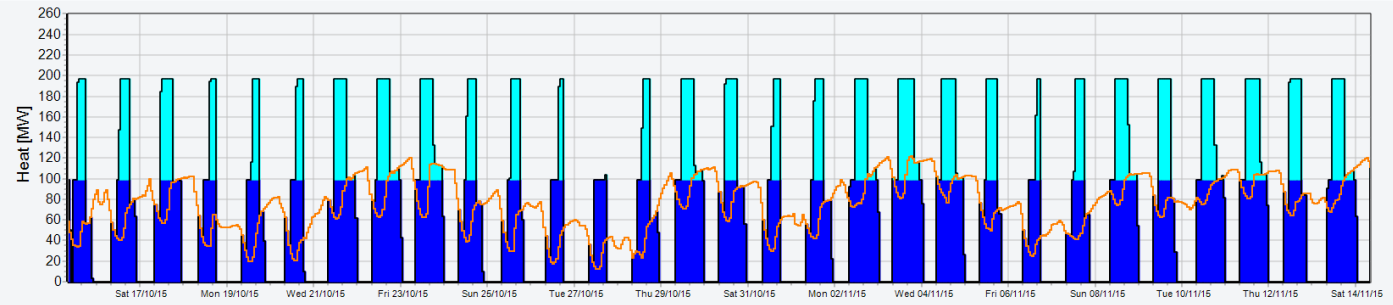

- CHP_1 CHP_2 $\square$ Peak boiler - Heat Demand

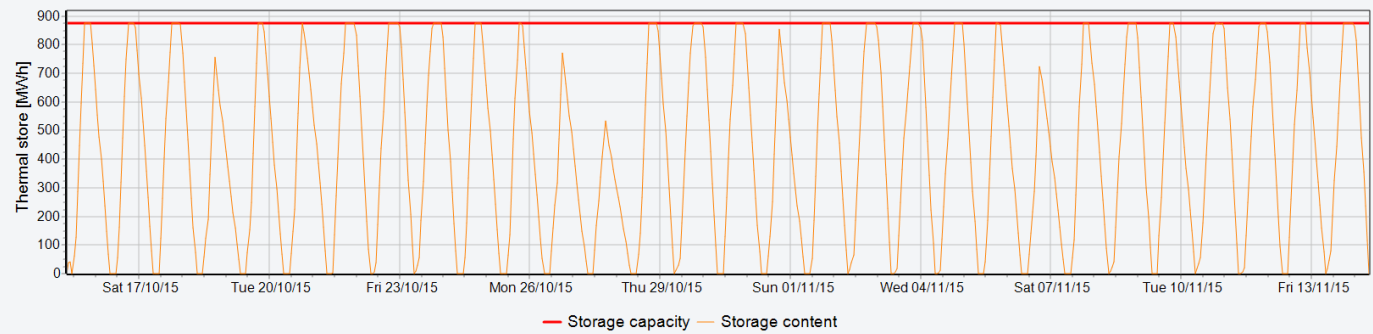

Fig. 4. The operation strategy in the start of the heating season.
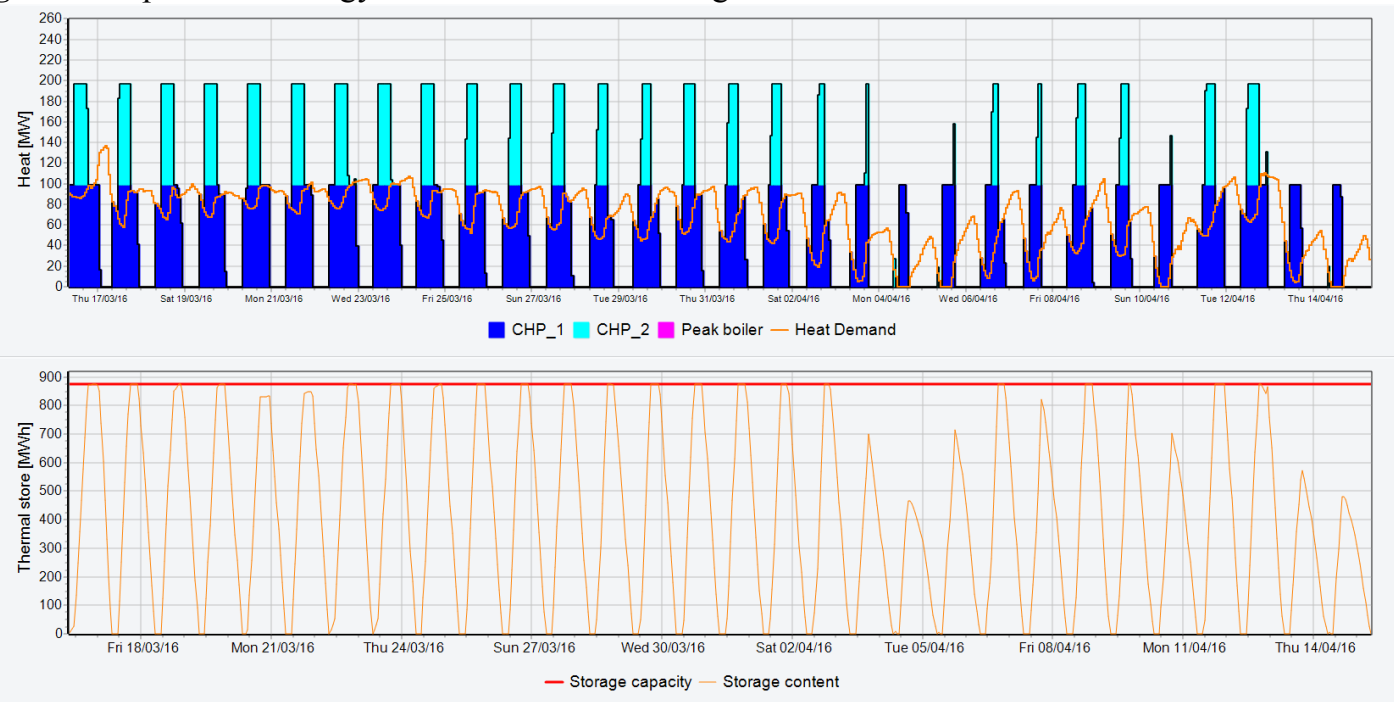

Fig. 5. The operation strategy in the end of the heating season.
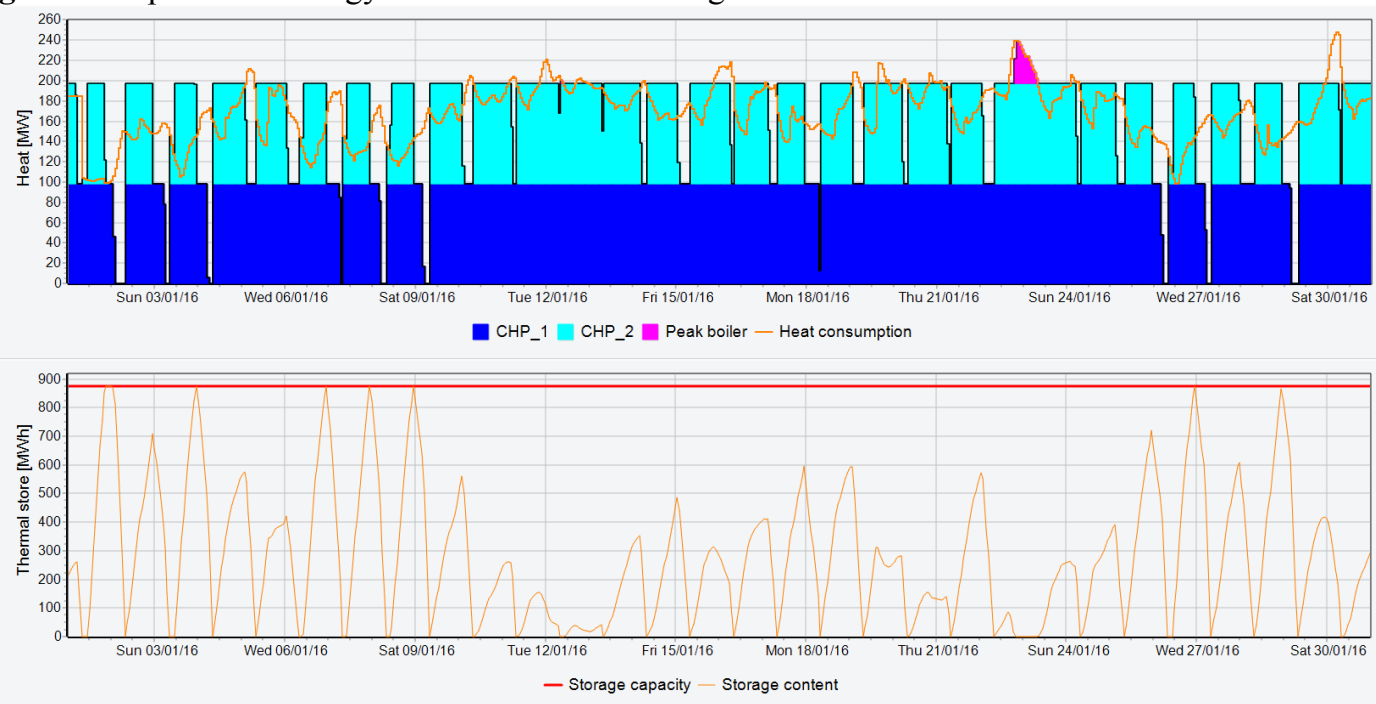

Fig. 6. The operation strategy in the mid-term of the heating season. 
Since the CHP plants undertakes the task of supplying heat for this area, we can know that the sale of heat doesn't change in Case A (only CHP system) and Case B (CHP+TES) because the heat demands remain unchanged through Eq.(5). However, Fig.7 shows that the electricity production increase in the peak-price and high-price period especially in the former, while drop significantly at valley-price period in Case B comparing with Case A. In Table 3, the sale of electricity can be seen in the sharp rise, which mainly caused by the rising income in higher electricity price period.

Comparing the computed results of the operation income of Shulan CHP Plant before and after adding the TES tank with volume of $24000 \mathrm{~m}^{3}$ in 2016 2017 heating season, it could be found that the operation income of the CHP plant with TES tank was added $2,342,165$ USD, increasing about $18.2 \%$. Meanwhile, adding the TES tank in CHP plant could reduce the use of the high cost peak-shaving heat resource. The operation time of the peak boiler has dropped from $262 \mathrm{~h}$ to $48 \mathrm{~h}$ in Case B, shortening $81.7 \%$. And the total fuel cost has been reduced by $11,305 \mathrm{USD}$, declined about $3 \%$.

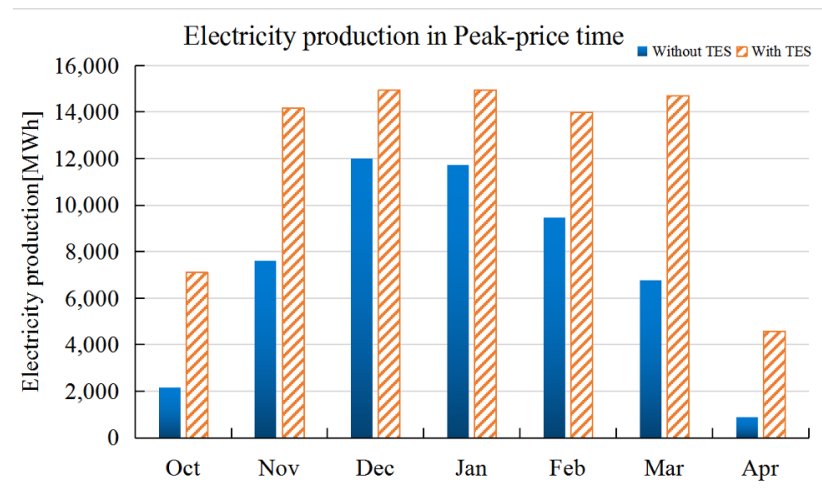

(a)

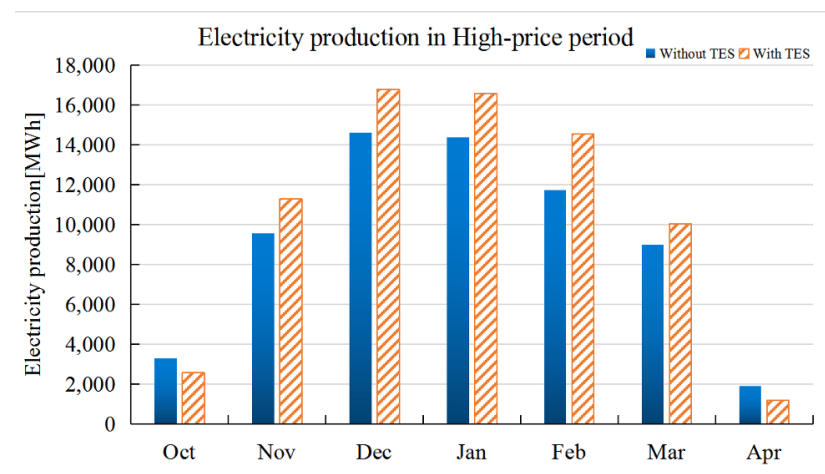

(b)

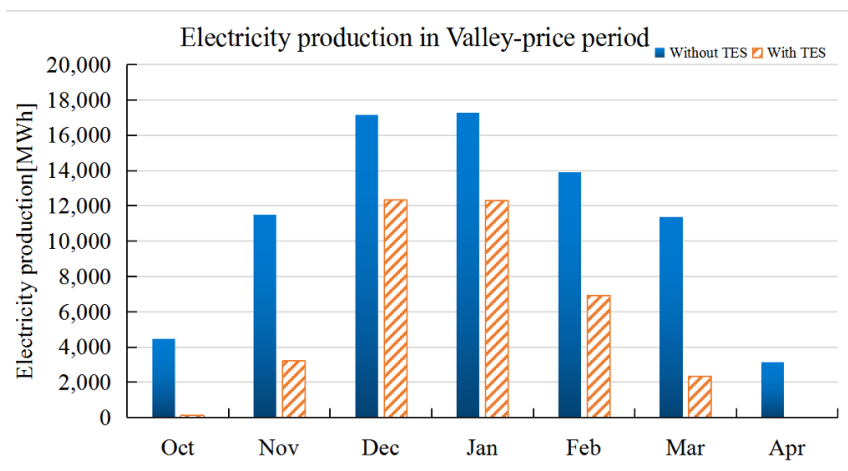

(c)

Fig.7. Electricity Production in different price of electricity period

\section{Conclusion}

In this paper we establish a mathematical model for a CHP plant with the TES tank. Then we choose a CHP plant in Shulan, Jilin as an example, using EnergyPRO software to find the optimum type of the TES tank in a three-tariff electricity pricing market. Thirdly we study the operation strategy and the economic benefit of the CHP plant with the selected optimal TES tank. The results shows:

1) Adding a TES tank enables the CHP plant to generate electricity on-grid as much as possible during the period when the price of electricity is relatively high. Meanwhile, the stable running time of the unit will increase, which can avoid the frequent adjustments of the CHP unit load and guarantee the operating efficiency of the unit.

2) After the configuration of the TES tank, the sale of electricity can be seen in the sharp rise. At the same time, the TES tank can reduce the use of peak-shaving heat resource with high cost. The case study shows in the whole heating season, the operation income of the CHP plants with TES tank was added 2,342,165USD, increased about $18.2 \% \%$. And the running time of the peaking heat source decreased from $262 \mathrm{~h}$ to $48 \mathrm{~h}$, shortening by $81.7 \%$, while the fuel cost has been reduced by $11,305 \mathrm{USD}$, declined about $3 \%$.

\section{Nomenclature}

$C_{T E S} \quad$ cost of the TES tank, yuan $/ \mathrm{m}^{3}$

$C_{f}(t) \quad$ hourly fuel cost of the CHP plant, MWh

$c_{l}(t) \quad$ fuel price of CHP unit, yuan/MWh

$c_{2}(t) \quad$ fuel price of peak boiler, yuan/MWh

$H H$ heating intensity of a certain hour, ${ }^{\circ} \mathrm{C} \cdot \mathrm{h}$

$H_{\text {peak }}(t)$ hourly heat production of peak boiler, MWh

$I_{h}(t) \quad$ sale of heat per hour, USD

$I_{e}(t) \quad$ sale of electricityt per hour, USD

$I_{A}(t) \quad$ operation income per hour, USD

$i_{h}(t) \quad$ heat price, USD/MWh

$i_{e}(t) \quad$ electricity price, USD/MWh

$k_{s} \quad k_{s}=1$ only when TES tank stores heat, otherwise $k_{s}=0$ 
$k_{r} \quad k_{r}=1$ only when TES tank releases heat, otherwise $k_{r}=0$

$P_{h i}(t) \quad$ hourly heat production in CHP unit $\mathrm{i}$

$P_{h i, \max }(t)$ hourly Max.heat production in CHP unit i

$P_{e i}(t) \quad$ hourly electricity production in CHP unit i

$P_{e i, \max }(t)$ hourly Max.electricity production in CHP unit i

$Q_{H D}(t)$ heat demand in a certain hour, MWh

$Q_{\text {TES }, ~}(t)$ hourly amount of heat storage, MWh

$Q_{\text {TES, }}(t)$ hourly amount of heat release, MWh

$Q_{T E S, s}$ total amount of heat storage per day, MWh

$Q_{T E S, r}$ total amount of heat release per day, MWh

$Q_{T E S} \quad$ capacity of the TES tank, MWh

$q_{o} \quad$ designed heat demand (determined by design), MW

$t_{w j} \quad$ average hourly outdoor temperature, ${ }^{\circ} \mathrm{C}$

$\gamma_{\mathrm{d}} \quad$ when $t_{w j}>18, \gamma_{\mathrm{d}}=1$; when $t_{w j}<18, \gamma_{\mathrm{d}}=0$

\section{References}

1. Ministry of Housing and Urban-Rural Development of the People's Republic of China. 2016 Statistical Report on Urban and Rural Construction (2017)

2. G. Romanovsky, J. Mutale, Implementation of heat production and storage technology and devices in power systems. Appl. Therm. Eng. 48, 296-300 (2012)

3. T. Nuytten, P. Moreno, D. Vanhoudt, L. Jespers, A. Solé, L. F. Cabeza, L. F. Comparative analysis of latent thermal energy storage tanks for micro-CHP systems. Appl. Therm. Eng. 59, 542-549 (2013)

4. M. J. Kim, H. Y. Song, J. B. Park, J. H. Roh, Optimization of CHP and thermal storage under heat demand. 2016 12th IEEE International Conference on Control and Automation (ICCA), 277-281 (2016)

5. S. Katulić, M. Čehil, Z. Bogdan, A novel method for finding the optimal heat storage tank capacity for a cogeneration power plant. Appl. Therm. Eng. 65, 530-538 (2014)

6. A. Fragaki, A. N. Andersen, D. Toke, Exploration of economical sizing of gas engine and thermal store for combined heat and power plants in the UK. Energy 33, 1659-1670 (2008)

7. Z. Wu, J. Wu, Feasibility study of district heating with CHP, thermal store and Heat Pump. Renewable Power Generation Conference IET (2013)

8. H. Lund, A. N. Andersen, Optimal designs of small CHP plants in a market with fluctuating electricity prices. Energy Convers. Manage. 46, 893-904 (2005)

9. Y. L. Liu, G. Y. Ren, J, Analysis of Heating Intensity in Harbin Based on Degree-hours Method. Nat. Resour. 33, 139-148 (2018)

10. S. K. Hu, J. B. Zhang, Z. Y. Song, Study on Transformation of Heating System and Analysis of Increasing Power But Decreasing Energy Consumption of Heating Turbines. Turbine Technol. 54, 135-138 (2012) 